\title{
Moving the Global Mental Health Debate Forward: How a Structural Competency Framework Can Apply to Global Mental Health Training
}

\author{
Amy Gajaria ${ }^{1} \cdot$ Jacob M Izenberg ${ }^{2} \cdot$ Viet Nguyen $^{2} \cdot$ Pragya Rimal $^{3} \cdot$ Bibhav Acharya $^{2,3} \cdot$ Helena Hansen $^{4}$
}

Received: 24 January 2019 / Revised: 14 May 2019 / Accepted: 21 May 2019 / Published online: 3 June 2019

(C) Academic Psychiatry 2019

In 2007, a series of articles was published in the Lancet advocating the use of global standards and internationally translatable interventions to narrow the gap between mental health treatment in low- and middle-income countries (LMICs) and high-income countries [1-4]. The ethics of the articles' recommendations and of the resultant resource mobilization has since faced criticism, particularly from experts in cultural psychiatry who argue that these articles' universalist approach to diagnosis and treatment overlooks the social and cultural context of mental health. Not only do these debates matter to the practice of global mental health, but they are important to education, particularly with the spread of training programs focused on this area [5]. In this paper, we review the arguments for and critiques of current approaches to global mental health. We then suggest, using an illustrative case, how the framework of Structural Competency [6] might be applied to improve global mental health training and bring important perspectives to mental health care in LMICs.

One approach to global mental health service delivery and education is embodied by the Movement for Global Mental Health (MGMH), which is a coalition launched in concert with a 2007 Lancet series on Global Mental Health. The MGMH is based on a few principal approaches including linking mental health care in LMICs to existing development goals and generally viewing the mental health care of those in LMICs within a biomedical model $[1,7,8]$. The focus of those involved in the MGMH has primarily been practical, devoted to modifying existing service-delivery approaches in order to "right [the] historical wrong" of inadequate access to mental

Amy Gajaria

amy.gajaria@camh.ca

1 University of Toronto, Toronto, Canada

2 University of California, San Francisco, San Francisco, USA

3 Possible, Nyaya Health Nepal, Achham, Nepal

4 New York University, New York City, USA health services in LMICs [9]. MGHM has introduced concepts such as a "treatment gap" to highlight a significant gap between those meeting psychiatric criteria for a mental illness and those actually receiving treatment [1], "task shifting"the practice of shifting aspects of care from physicians to lay health workers, - and "scaling up,"- - finding strategies to bring evidence-based treatment to a large portion of the population $[1-4,10,11]$.

Prior to the launch of the MGMH, academic attention to the mental health of those in non-Western societies, the majority of which are (or exist within) LMICs, largely fell under the purview of cultural psychiatry [9]. This field has approached the issue of mental health concerns in non-Western societies from an anthropological perspective, with a focus on understanding local idioms of distress and treatment approaches [12]; its members are among the MGHM's most frequent critics, arguing that all psychiatric knowledge is culturespecific [13] and that applying treatment paradigms developed in the West to non-Western settings without a deep understanding of the local culture risks misattributing to mental illness a range of other types of experiences. On a practical level, they argue, this could reduce the availability of traditional and historical methods for alleviating suffering to those in distress, possibly worsening, rather than improving, emotional and mental wellbeing $[13,14]$.

Though both MGMH and cultural psychiatry acknowledge the importance of considering social determinants of health as they relate to mental health conditions, critics of MGMH have noted the movement's limited engagement in dialogue related to race, economic instability, war, or power structures within or between LMICs $[9,13,15]$. Though the lens of cultural psychiatry allows for social and political context in examining mental health difficulties in LMICs, it too does not offer an approach to addressing political forces affecting mental health. Both cultural psychiatry and the MGMH consider the social determinants of health, but have traditionally looked at determinants such as income and literacy without attending to greater political and economic processes that lead to disparate incomes and literacy rates 
$[16,17]$. China Mills, in her book Decolonizing Global Mental Health, calls this the "psychiatrization of economic suffering" [18]. As Derek Summerfield writes, through this process, distress "is relocated from socio-political space, a public and collective problem, to mental space, a private and individual problem" [19]. Participants in a workshop examining the future directions for global mental health training reported that addressing the social and political determinants of health was an unmet need in global mental health training [20]. At the moment, neither MGHM nor cultural psychiatry has developed a clear framework to help learners approach the larger socio-political structures affecting the mental health of people in LMICs. We suggest that structural competency could be an option to fill this gap.

\section{Structural Competency-a Brief Introduction}

The term structural competency refers to a set of knowledge and skills that equip medical professionals to identify and act on the social and political arrangements that create systemic inequalities in health [6]. The "structures" in structural competency are social and institutional systems, as well as the public policies and embedded hierarchies that fund and govern such systems. These structures dictate the terms by which groups of people - whether defined by race, gender, sexuality, immigration status, religion, or any other characteristiceither exercise or lack power, gain access to resources, perceive fairness or suffer injustice. In a structural competency framework, these are the terms that influence how individuals and communities experience health or illness.

Metzl and Hansen (2014) suggest five core competencies that collectively make up structural competency for clinical practitioners. They include "recognizing the structures that shape clinical interactions," "developing an extra-clinical language of structure," "rearticulating 'cultural' presentations in structural terms," "observing and imagining structural intervention," and "developing structural humility" [6]. Practically, these competencies guide health providers in how to address the structures that shape the health of populations, how to think critically about the limitations such structures impose upon our clinical treatments, and how to engage in altering these structures directly. Similar to critics of MGMH, advocates of structural competency argue that failing to consider the socio-political context in which patients live misses a vital piece of the mental health of people in LMICs.

\section{Illustrative Case Study and Discussion}

\section{Clinical Case}

"Mrs. K" is a 19-year-old, lower caste, married woman from rural Nepal far from the center of power in Kathmandu. She presented to a local public hospital with generalized body weakness, fainting spells, and stomach pains. Due to limited transportation options, her family had to carry her for nearly half of the 2day journey to the hospital. On initial evaluation, she is nonresponsive, and occasionally groans with her eyes closed. She does not follow commands, and grimaces to non-localized pain. Other than mild tachycardia, her vital signs and the physical exam are unremarkable. The primary care provider refers her to the emergency room for observation, and orders intravenous fluids and basic labs to rule out anemia and infection. The primary care provider, during a recent series of lectures hosted by a visiting GMH fellow, learned that mental illness in Nepal can present as physical symptoms, and as such considers whether Mrs. K's presentation could have a psychiatric cause.

Fortunately, as part of expanding access to mental health services, the public hospital recently hired a psychosocial counsellor in their outpatient department. This counsellor's work was supplemented by that of a visiting psychiatrist, as there was no full-time psychiatrist in the area. Mrs. K was referred to this counsellor who was able to elicit more history from Mrs. K.'s family. As a result of persistently poor economic options in the region in which Mrs. $\mathrm{K}$ lives, her husband had to leave a month prior to find work in India, leaving Mrs. K with their 9-month-old son; he will likely return in six months. Initially, the psychosocial counsellor did not see a psychiatric reason for Mrs. K's presentation, but agreed to see Mrs. K individually just in case.

Mrs. K's labs results were normal and she received one liter of normal saline. After a night spent in observation, she was no longer in acute distress and was referred to the psychosocial counsellor for re-evaluation. Interviewed alone, Mrs. K provided more history about her family: her mother died about a year ago in a road accident, and her father left for India when she was very young. Mrs. K also gradually provided a history of both witnessing domestic violence as a child and experiencing domestic violence from her husband. She denied suicidal ideation, or any symptoms of psychosis. However, she was not very engaged with interview, and quite guarded. After hearing more of Mrs. K's story, the counsellor felt she might have both depression and conversion disorder. The psychosocial counsellor had received training in addressing both conditions from a culturally appropriate psychotherapeutic approach and could provide care for free in the outpatient department rather than requiring Mrs. $\mathrm{K}$ to travel to Kathmandu. Given this diagnosis by the psychosocial counsellor, the primary care provider provided fluoxetine.

Despite both being of the same cultural background as Mrs. $\mathrm{K}$ and following evidence-based guidelines for the treatment of depression and conversion disorder, Mrs. $\mathrm{K}$ continued to experience symptoms including dizziness and "a feeling like my body was not my own." After psychoeducation was provided to Mrs. K and her family about mental illness, Mrs. K started to improve. 
The psychosocial counsellor was left puzzled by this case. She was happy that Mrs. K improved, but wondered whether there was more that she could have done. As a result of Mrs. $\mathrm{K}$ 's case, the psychosocial counsellor and others in the hospital developed an intervention to provide more support for women such as Mrs. $\mathrm{K}$ who, as a result of being poor women in rural settings, have a lack of access to economic resources which prevents their ability to leave situations of domestic violence. The Women's Groups implemented in rural Nepal allowed women to meet and discuss their lives and to explore possible economic opportunities for themselves.

\section{Case Discussion}

The case above highlights a number of determinants of health, including poor access to healthcare, domestic violence, varying cultural models of illness, and poverty. Contributions from MGMH and cultural psychiatry were important in addressing some of these determinants. For example, to address poor access to resources, Mrs. K was provided with mental health care using a task-shifting model. Lessons from cultural psychiatry led to the treatment being delivered by providers who shared Mrs. K's culture, an understanding of how domestic violence contributed to her current presentation, and the identification of a somatic presentation of mental distress, though cultural psychiatrists may still argue that using diagnoses based in the DSM5 is intrinsically problematic. We also highlight how some aspects of Mrs. K's care were not addressed by either the MGMH or cultural psychiatry, particularly the issues of migratory labor and the lack of access to economic resources; in the last paragraph, we highlight how thinking structurally about mental health problems in LMICs resulted in an intervention that providers may not historically have considered as related to health (the development of Women's Groups), one that may ultimately have a durable impact on women's ability not only to support each other emotionally, but through cooperative efforts, economically as well.

We note here that this client has a history of experiencing domestic violence. A program that considers this problem from a structural perspective may attend to the situation of women in Nepal who, until recently, were not legally able to own property and who often are entirely financially dependent on the men in their lives. A structural competency approach would differ from a cultural psychiatry approach in not only noting that mental distress may be a patient's individual response to living in a situation to which there is no feasible route of escape, but would also offer tools to understand and address the causes of domestic violence. For example, training using a structural competency framework could focus on the need for mental health providers in Nepal to explicitly examine how a lack of legal and social protections for women affect their mental and physical health and consider the development of domestic violence programs to serve women such as Mrs. K.
This client and her family also come from a region of Nepal located far from the center of power in the capital. A long history of neglect of this region has resulted in few economic opportunities and a need for male members of the household to depend on seasonal migration for work, placing immense stress on those men while leaving women to be responsible for maintaining not only the household, but care of the land and farm. Furthermore, the lower-caste background of this patient means that she and her family have faced a lengthy history of discrimination that has until recently been codified Nepalese law. While approaches from MGMH might pragmatically address this by increasing access to resources in underserved regions, and cultural psychiatrists might (justifiably) ask whether distress in this setting should even be called mental illness, neither offer an obvious framework to think about nor address these forces at a political level. Structural interventions meanwhile might include primary care providers engaging in efforts related to address the neglect of this region; such activities could include advocacy focusing on the need for better transportation, improved economic opportunities, and greater services for women whose husbands have had to migrate for work.

\section{What Next? The Use of Structural Competency in Global Mental Health Training}

While many have criticized global mental health training for failing to address structural concerns, to our knowledge, there has not been a clear model for training practitioners in global mental health to address systematic inequalities and other structural issues. Such an approach can be tailored to trainees with varying degrees of interest in global mental health, from fellowships, to specific training tracks, to considerations for trainees who may only do brief experiences in LMICs. The experience of Kronfol et al. (2016) developing a Global Mental Health track for psychiatry residents at Cornell University suggests that there is an appetite for curricula addressing political structures within global mental health training and that such training is feasible [21]. The new Global Mental Health Fellowship at UCSF features structural determinants of mental health as one of its primary educational domains, within which are included series of competencies closely reflecting the structural competency framework [22]. Including global mental health as a topic in training programs that teach psychiatric residents to intervene on structural determinants of mental health locally can provide education for trainees who might be doing single opportunities in LMICs. These approaches use didactic and experiential teaching informed by the social sciences, hands-on legislative and community advocacy, and immersion and observation in community, jail, and prison settings and can be adapted to include global mental health issues [23-25]. We suggest that a structural approach can underlie various curricula as a synthesizing 
force, opening additional avenues for approaching the complexities of mental health care for people in LMICs for multiple kinds of trainees at multiple levels of training.

If addressing structural determinants of mental health in global settings sounds like a big task, it is. The concept of cultural humility - which asks clinicians for curiosity regarding the cultural context of their patients, and to collaborate with patients to draw on patients' self knowledge, thereby levelling power inequalities between clinicians and patients - has been deployed out of recognition that the model of an omniscient clinician unilaterally exercising knowledge has the potential to reinforce inequalities. Similarly, structural humility calls on clinicians to collaborate with, and recognize the expertise of, community organizations and professionals in other disciplines, while acknowledging the reality that structural change requires patience. Humility is particularly relevant to global mental health; it is difficult to fully grasp the social, political, and economic landscape of another region. Global mental health work, and therefore global mental health training, must recognize the complex forces at work in a place, seek the expertise of those with deep experiential knowledge of the community, and collaborate with them in structural interventions.

Funding There was no funding for this project.

\section{Compliance with Ethical Standards}

Ethical Considerations n/a (no human subjects)

Conflict of Interest Dr. Gajaria receives salary support for her research from the O'Brien Fund. On behalf of all authors, the corresponding author states that there is no conflict of interest.

\section{References}

1. Prince M, Patel V, Saxena S, Maj M, Maselko J, Phillips MR, et al. No health without mental health. Lancet. 2007;370(9590):859-77.

2. Patel V, Araya R, Chatterjee S, Chisholm D, Cohen A, De Silva M, et al. Treatment and prevention of mental disorders in low-income and middle-income countries. Lancet. 2007;370(9591):991-1005.

3. Chisholm D, Flisher a J, Lund C, Patel V, Saxena S, Thornicroft G, et al. Scale up services for mental disorders: a call for action. Lancet. 2007;370(9594):1241-52.

4. Saxena S, Thornicroft G, Knapp M, Whiteford H. Resources for mental health: scarcity, inequity, and inefficiency. Lancet. 2007;370(9590):878-89.

5. Lam JSH, Gajaria A, Matthews DM, Zaheer J. Bridging cultural psychiatry and global mental health: a resident-led initiative. Acad Psychiatry. 2016;40(4):729-30.
6. Metzl JM, Hansen H. Structural competency: theorizing a new medical engagement with stigma and inequality. Soc Sci Med. 2014;103:126-33.

7. Patel V, Boyce N, Collins PY, Saxena S, Horton R. A renewed agenda for global mental health. Lancet. 2011;378(9801):1441-2.

8. Patel V, Saxena S, Lund C, Thornicroft G, Baingana F, Bolton P, et al. The Lancet Commission on global mental health and sustainable development. Lancet. 2018;392(10157):1553-98.

9. Whitley R. Global mental health: concepts, conflicts and controversies. Epidemiol Psychiatr Sci. 2015;24(4):285-91.

10. Jacob KS, Sharan P, Mirza I, Garrido-Cumbrera M, Seedat S, Mari JJ, et al. Mental health systems in countries: where are we now? Lancet. 2007;370(9592):1061-77.

11. Eaton J, McCay L, Semrau M, Chatterjee S, Baingana F, Araya R, et al. Scale up of services for mental health in low-income and middle-income countries. Lancet. 2011;378(9802):1592-603.

12. Kirmayer LJ. Beyond the "new cross-cultural psychiatry": cultural biology, discursive psychology and the ironies of globalization. Transcult Psychiatr. 2006 Mar;43(1):126-44.

13. Kirmayer LJ, Pedersen D. Toward a new architecture for global mental health. Transcult Psychiatr. 2014;51(6):759-76.

14. Fernando GA. The roads less traveled: mapping some pathways on the global mental health research roadmap. Transcult Psychiatry. 2012;49(3-4):396-417.

15. Koplan JP, Bond TC, Merson MH, Reddy KS, Rodriguez MH, Sewankambo NK, et al. Towards a common definition of global health. Lancet Lond Engl. 2009;373(9679):1993-5.

16. Raphael D. Social determinants of health: present status, unanswered questions, and future directions. Int J Health Serv. 2006;36(4):651-77.

17. Das A, Rao M. Universal mental health: re-evaluating the call for global mental health. Crit Public Health. 2012 Dec;22(4):383-9.

18. Mills C. Decolonizing global mental health: the psychiatrization of the majority world. London: Routledge; 2013.

19. Summerfield D. Afterword: against "global mental health.". Transcult Psychiatry. 2012;49(3-4):519-30.

20. Kohrt BA, Marienfeld CB, Panter-Brick C, Tsai AC, Wainberg ML. Global mental health: five areas for value-driven training innovation. Acad Psychiatry J Am Assoc Dir Psychiatr Resid Train Assoc Acad Psychiatry. 2016;40(4):650-8.

21. Kronfol Z, Al-Amin H, Haddad N, Streletz L, Gordon-Elliott J, Marzuk P. Teaching psychiatry on the global scene: the Cornell University experience. Acad Psychiatry. 2016;40(4):698-700.

22. Buzza C, Fiskin A, Campbell J, Guo J, Izenberg J, Kamholz B, et al. Competencies for global mental health: developing training objectives for a post-graduate fellowship for psychiatrists. Ann Glob Health. 2018;84(4):717-26.

23. Hansen H, Rohrbaugh R, Braslow J. Structural competency for psychiatry residents: a call to act on systemic discrimination and institutional racism. JAMA Psychiatry. 2018;75(2):117-8.

24. Metzl J, Hansen H. Structural competency and psychiatry. JAMA Psychiatry. 2018;75(2):115-6.

25. Kirmayer LJ, Kronick R, Rousseau C. Advocacy as key to structural competency in psychiatry. JAMA Psychiatry. 2018;75(2):119-20.

Publisher's Note Springer Nature remains neutral with regard to jurisdictional claims in published maps and institutional affiliations. 